\title{
Recovery Following Hurricane Rita: A Pilot Study of Preexisting and Modifiable Aspects of Positive Change
}

\section{Susan E. Borja and Jennifer L. Callahan}

Facets of personality from the Big 5 model, familial coping mechanisms, and interpersonal support were selected to predict perceived benefits and subjective well-being with 43 participants from varied ages, income levels, and ethnicities who experienced a natural disaster. Results indicate positive changes were predicted by distinct variables (mental healthiness was predicted by high agreeableness, passive appraisal, and reframing, accounting for $43 \%$ of the variance, whereas perception of benefits was predicted by high conscientiousness and seeking social support, which accounted for $50 \%$ of the variance). Thus, it appears that long-standing, pretraumatic individual and familial differences predict these posttraumatic outcomes.

Keywords: trauma; posttraumatic stress; disaster
$\mathrm{E}$ xposure to natural disaster is known to be associated with both short-term and longterm psychological and physical health problems (for reviews, see Bourque, Siegel, Kano, \& Wood, 2006; Miller \& Kraus, 1994; Norris, Murphy, Baker, \& Perilla, 2004). Such disasters include a unique trauma variable in which extensive physical resources may be destroyed, and previous research has found that the extent of an individual's property loss is predictive of emotional distress (Briere \& Elliot, 2000; Norris, Perilla, Riad, Kaniasty, \& Lavizzo, 1999).

Although less is known about positive change than negative sequelae following natural disasters, within the broader trauma literature positive change is increasingly addressed (see, e.g., Cryder, Kilmer, \& Tedeschi, 2006; Linley, Joseph, Cooper, Harris, \& Meyer, 2003; Tedeschi \& Calhoun 1995; Woodward \& Joseph, 2003). It appears that at least half of trauma survivors may endorse some form of growth or positive change (Tedeschi \& Calhoun, 1995), including survivors of

From the Department of Psychology, Oklahoma State University, Stillwater, Oklahoma (SEB); Department of Psychology, University of North Texas, Denton, Texas (JLC); and Department of Psychiatry, Yale School of Medicine, New Haven, Connecticut (JLC).

Address correspondence to: Jennifer L. Callahan, PhD, ABPP, Department of Psychology, University of North Texas, PO Box 311280, Denton, TX 76203-1280; e-mail: jennifercallahan@unt .edu. natural disasters (Cryder et al., 2006; McMillen, Smith, \& Fisher, 1997; Vazquez, Cervellon, Perez-Sales, Vidales, \& Gaborit, 2001).

As a result of this growing body of research, it is now possible to begin formulating predictive outcome models that may facilitate identification of service needs and identify areas of strength for survivors following natural disaster experiences. A full review of the literature on the hypothesized predictive variables is beyond the scope of this brief report, but a summary of prominently researched variables follows.

Several investigators have explored the relationship between trauma and personality from the Big 5 (i.e., neuroticism, extraversion, openness, agreeableness, and conscientiousness) perspective (see, e.g., Costa \& McCrae, 1992; Funder, 2001; O’Connor \& Dyce, 2002). More specifically, extremely low scores on agreeableness have been found to correlate with trauma-induced distress (Fauerbach, Lawrence, Schmidt, Munster, \& Costa, 2000; Nightengale \& Williams, 2000; Talbert, Braswell, Albrecht, Hyer, \& Boudewyns, 1993). Low conscientiousness scores have also been found to correlate with distress (Fauerbach et al, 2000). In contrast, high scores on conscientiousness and agreeableness have been found to promote resilience (Riolli, Savick, \& Cepani, 2002). Beyond resiliency, a recent meta-analysis found that benefit finding was related to greater optimism (Helgeson, Reynolds, \& Tomich, 2006). 
Familial and general social support have also been found to promote positive outcomes (Brewin, Andrews, \& Valentine, 2000; Frazier, Tashiero, Berman, Steger, \& Long, 2004; Ozer, Best, Lipsey, \& Weiss, 2003). In fact, the simple presence or absence of a support network has been found to be predictive of distress, regardless of the quality of social support (Joseph, Dalgleish, Thrasher, \& Yule, 1995). However, at this time, no studies have yet been able to determine why even negative support correlates with positive outcomes (Ullman, 1996). The subjectively experienced, and qualitatively labeled, negative social support occurs when one attempts to be supportive but, in essence, provides a potentially damaging support comment or behavior such as "you should forget about it" or questioning "why were you there" to the trauma victim. These types of responses are not unheard of after any trauma. However, they appear to have potentially become more prevalent for survivors of hurricanes because of the large number of damaging storms in the past few years. Residents in hurricane-prone areas may be dismissed or seen partially to blame for living in an area where a hurricane might strike. For example, soon after Hurricane Katrina, a poll by TIME magazine indicated that $57 \%$ of the respondents blamed the victims themselves for the relief problems ("TIME Poll Results: Hurricane Katrina," 2005).

The findings presented here represent preliminary data gathered to lend support to a larger model for understanding the differing outcomes following traumatic stressors (e.g., distress, growth, etc.). This inquiry is focused specifically on predictors of selfreported positive changes following a natural disaster for the purpose of understanding how these may be facilitated following mass exposure to a traumatic stressor. Although there is an emerging body of literature, some researchers have mistakenly used various terms for positive changes (i.e., resiliency, posttraumatic growth, benefit finding, mental healthiness) interchangeably. This study further seeks to elucidate if these terms do refer to a single latent construct as suggested by using these terms interchangeably or are separate forms of positive outcomes.

Given the existing body of research on benefit finding (see Helgeson et al., 2006, for a meta-analytic review of benefit finding and growth), this study aims to further the field by elucidating the distinction between benefit finding and mental healthiness that may emerge after exposure to a traumatic event. At this time, there is no other cross-sectional research with hurricane-exposed populations exploring the individual and familial coping characteristics to predict positive outcomes in the literature. As a pilot study, this article seeks to clarify the various ways in which positive changes may occur in the aftermath of disaster and what uniquely predicts each. Specifically, the preexisting factors of personality, familial coping mechanisms, and interpersonal support were explored, in conjunction, to determine their contributions to the constructs of positive change. Taken together, the aims of this study are meant to lay a foundation on which future research may build with other unique samples (in terms of population and traumatic exposure) to further develop causal models of outcomes and to look more predicatively at these outcomes.

\section{Method}

\section{Participants}

In 2005, approximately 6 weeks after Hurricane Rita struck the southeastern portion of the United States, a convenience sample of 43 adult South Florida residents were individually recruited for participation during neighborhood cleanup efforts. Participants in this study were fairly representative of a Floridian sample for ethnicity and were from varied economic, educational, and age groups and included 16 men and 27 women who ranged in age from 18 to 71 years $(M=39.42, S D=15.79$, median age 38). The majority of the participants in this sample were Caucasian (58\%), though $14 \%$ were African American, $18.6 \%$ were Hispanic, $7 \%$ were Asian, and $2.3 \%$ identified themselves as other. Income ranged from $\$ 8,000$ to $\$ 550,000$, with an average income of $\$ 66,085, S D=91,543$ (median income of $\$ 38,000)$. Education level ranged from middle school $(2.3 \%)$ to postgraduate $(14 \%)$, with most participants $(81.4 \%)$ completing at least some years in college.

\section{Procedures}

On organized breaks from formal neighborhood cleanup efforts, residents who experienced Hurricane Rita were approached and informed about the purpose of the study. This sampling method is common among natural disaster samples (Norris, 2007). Following informed consent, packets of questionnaires were provided and asked to be returned by 
the end of the day. All participants were treated in accordance with the Ethical Principles of Psychologists and Code of Conduct (American Psychiatric Association, 2002).

\section{Measures}

NEO-Five Factor Inventory (NEO-FFI). The Revised NEO Personality Inventory (NEO-PI-R; Costa \& McCrae, 1992) is a psychometrically robust measure characterizing adult personality along the Big 5 constructs. Derived from this measure, the NEO-FFI is a short form consisting of 60 items reflecting the same five major domains (i.e., neuroticism, extraversion, openness, agreeableness, and conscientiousness). Internal consistency for this measure was good overall $(\alpha=$ .83 ), although subscale $\alpha$ s ranged from .44 to .87 .

Family Crisis Oriented Personal Evaluation Scales (F-COPES). The F-COPES (McCubbin, Olson, \& Larsen, 1981) is a reliable 30-item self-report questionnaire that identifies familial approaches to difficult or problematic situations. Factor analysis has previously established 5 subscales, including acquiring social support (ability to actively engage in acquiring support from relatives, friends, neighbors, and extended family), reframing (capability to redefine stressful events to make them more manageable), seeking spiritual support (ability to acquire spiritual support), mobilizing the family to acquire and accept help (ability to seek out community resources and accept help from others), and passive appraisal (ability to accept problematic issues, minimizing reactivity). Internal consistency for the F-COPES was good with $\alpha$ s ranging from .70 to .88 , with the exception of the mobilizing family subscale, which had a reliability of .32 .

Interpersonal Support Evaluation List (ISEL). The ISEL (Cohen, Mermelstein, Kamarck, \& Hoberman, 1985 ) is a 48-item self-report inventory that assesses perceived availability of social resources and has been widely used to measure social support among trauma survivors (Dutton, Hohnecker, Halle, \& Burghardt, 1994). Four subscales have emerged in factor analysis: tangible assistance (providing material goods), appraisal (the perceived availability of someone to talk about one's problems), self-esteem (availability of a positive comparison to others), and belonging (Cohen et al., 1985). The ISEL subscales' internal reliability ranged from .77 to .84 .
Mental Health Continuum-Short Form (MHC-SF). The MHC-SF (Keyes, 2005) is a brief version of the 39-item long-form previously used to assess a continuum of mental healthiness with adults (Keyes, 2002, 2005). This 14-item, self-administered questionnaire asks respondents how often in the past month they have felt 6 symptoms of positive affect (e.g., happy, satisfied) on a 5-point Likert-type scale. These 6 symptoms tap three dimensions of subjective well-being as it pertains to mental healthiness: emotional well-being, psychological well-being, and social well-being. Excellent internal consistency was found with the current sample $(\alpha=.92)$.

Perceived Benefits Scale (PBS). The self-report PBS is a 38-item measure of subjective positive life changes after negative traumatic events (McMillen \& Fisher, 1998). Example items intended to measure gains include "Because of this event, I show more caring to others" and "This event taught me I can handle anything." Total scores (range 0-109) obtained by current participants $(M=50.90, S D=$ 29.38) fell beyond the range (14.35-47.85) obtained from other samples reported in the literature (Borja, Callahan, \& Long, 2006; Joseph, Linley, \& Harris, 2004; McMillen \& Cook, 2003). Excellent internal reliability was calculated for the PBS $(\alpha=0.97)$.

\section{Results}

All analyses were conducted using an $\alpha$ level of .05 (unless otherwise stated) in statistical tests using the Statistical Package for the Social Sciences version 15.0 (SPSS, 2006). Participants who experienced property loss (range, $10 \%$ to $90 \%$ of property lost; $n=19$ ) were compared with those who reported no direct loss $(n=21)$ on the outcome measures. No significant differences were found on outcome measures (PBS and MHC-SF). These groups were, therefore, combined for subsequent analyses pertaining to these measures. Relationships between variables are presented in Table 1.

\section{Preliminary Analyses}

Two linear stepwise regressions were calculated to examine the relative impact of personality, family, and general support variables in predicting positive outcomes. The first linear stepwise regression was performed using the PBS (a measure of broad 


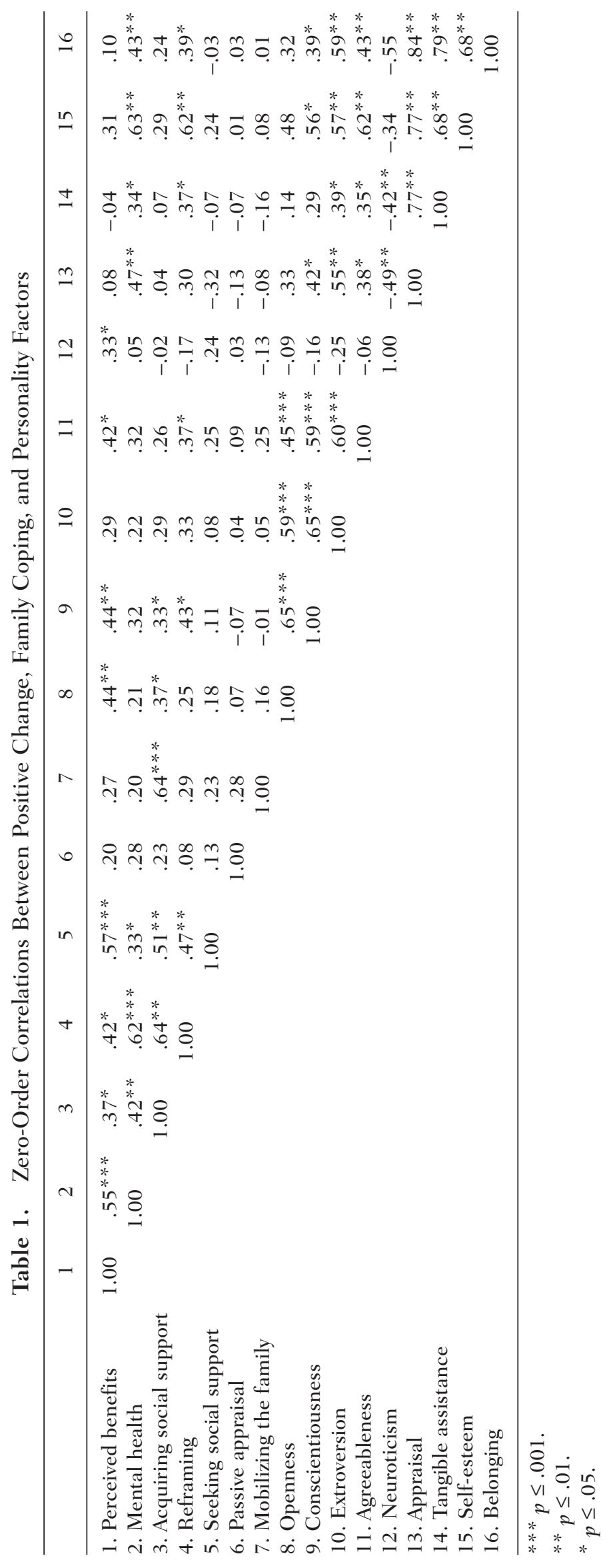


perceived benefits) composite score as the criterion. Personality traits from the NEO-FFI and support variables (subscales from the F-COPES and ISEL) were used to predict perceived benefits. The only personality variable that entered the equation was conscientiousness $(\beta=.37)$. Seeking social support, as measured on the F-COPES, also significantly contributed to the model $(\beta=.47)$. Together, these two variables accounted for $43 \%$ of the variance in perceived benefits, $F(2,41)=9.51, p<.01$. Calculated tolerance (.96) and power (.94) were excellent.

A second linear stepwise regression was then performed using the MHC-SF, an affective foil to depression, total score as the criterion. Similar to the first regression, personality, family, and general support variables were permitted to enter. In contrast to the first regression, only agreeableness $(\beta=.25$; from the NEO-FFI), reframing ( $\beta=.50$; from the F-COPES), and passive appraisal ( $\beta=0.32$; from the F-COPES) met significance to be included in the model. Together, these three variables accounted for $50 \%$ of the variance in scores on the MHC-SF, F(3, 40) = 7.56, $p<.01$. Calculated tolerance $(.90$ to .96$)$ and power (.94) were again excellent.

\section{Secondary Analyses}

Given the small sample size of this pilot data set, secondary regression analyses were conducted to evaluate the strength of the relationships that were found in the initial regressions. Again, power was excellent for the primary analyses, but we wanted to be sure that the significant findings were not produced by the limited variance associated with a smaller sample size. By forcing in the variables that did not enter during primary analyses and only then permitting the variables of interest (based on the primary analyses) to enter the regression equations, we can examine whether the predicative variables found to be statistically significant in the primary analyses remain significant even when other relevant predictors are considered in the equations.

First, using PBS as the criterion, the interpersonal support, family coping, and personality variables that did not enter in the initial stepwise regression were forced to enter in Step 1. These variables accounted for $60 \%$ of the variance. Second, conscientiousness and seeking social support were forced into the equation in Step 2, significantly accounting for an additional $18 \%$ of the variance. Thus, even when other variables are forced into the equation first, the variables of interest still make a contribution above and beyond the other variables. This is important given the small sample size and suggests that the variables are distinct in their contribution and that the findings are not an artifact of small differences.

The same procedure was followed to evaluate the second stepwise regression conducted as was done in the preliminary analyses with MHC-SF as the criterion. Interpersonal support, family coping, and personality variables that did not enter in the initial stepwise aggression were forced in Step 1 and accounted for $54 \%$ of the variance. In Step 2, passive appraisal, reframing, and agreeableness were forced into the equation, accounting $10 \%$ of the variance beyond that accounted for by the variables entered in the preceding step. Although these secondary analyses account for less variance than the corresponding primary analyses, they further support the conclusion that conscientiousness and seeking social support are important predictive variables in the perception of broad benefits and that passive appraisal, reframing, and agreeableness are specifically important in understanding the subjective sense of well-being.

Finally, to demonstrate the superiority of the proposed models over alternative models, the variables for each respective model were forced into the alternative model. When passive appraisal, reframing, and agreeableness were forced into a model with PBS as the criterion, only $30 \%$ of the variance could be explained. Next, seeking social support and conscientiousness were forced into a model with MHC-SF as the criterion. These variables accounted for only $20 \%$ of the variance, far less than the proposed model, indicating that the predictive models are not interchangeable and that the constructs of perceived benefits and mental healthiness are distinct.

\section{Discussion}

The pilot findings presented here lend support to the establishment of a model for understanding the differing outcomes following traumatic stressors (e.g., distress, growth, etc.). Results of this study were consistent with previous research indicating significant positive relationships between variables and with hypotheses that personality, family coping, and support variables would be related to outcomes (Brewin et al., 2000; Frazier et al., 2004; Ozer et al., 2003; Riolli et al., 2002). Given that this is a pilot 
study, we strongly encourage future research investigating similar relationships.

Results of this study hold particular importance for spokespersons of organizations or political figures (i.e., mayor, governor, or president) that often make public remarks following mass traumas in an attempt to address the tragedy and at times offer direction for the public. These individuals may seek direction from national (the National Institute of Mental Health, the Substance Abuse and Mental Health Services Administration, etc.) or local mental health professionals (experts in the field, local psychologists, etc.) in formulating their comments and assurances to the public. It is our recommendation that such public remarks emphasize actions that may foster positive outcomes, particularly if it is at no cost (in time or effort) to primary and secondary responders who attempt to address physical and mental health needs.

This study also helps clarify to some extent the promising literature on positive outcomes following trauma. Although there is an emerging body of literature exploring the absence of pathology or actual gains, some researchers have mistakenly used various terms (i.e., resiliency, posttraumatic growth, benefit finding, mental healthiness) interchangeably. Positive changes, such as the perception of benefits and mental healthiness, which may occur following a traumatic experience, appear to be comprised of unique variables, strongly indicating that positive change following trauma exposure is not a single latent construct. More specifically, at least two distinct forms of positive change are predicted by distinct variables. The first form, mental healthiness (characterized as emotional well-being, psychological well-being, and social well-being), was significantly predicted by high agreeableness, calm acceptance (i.e., passive appraisal), and the ability to think differently about the traumatic events (i.e., reframing). Thus, it appears that factors that predict mental healthiness are largely long-standing individual and familial differences that likely preexisted trauma exposure and apparently flourished in the face of adversity. Stated another way, the distinct forms of positive change were predicted by unique variables that were longstanding (personality characteristics and family characteristics). However, the positive changes themselves were not long-standing as they reflect a recent shift in the wake of the natural disaster.

Identification of individuals responding in this manner may be beneficial, particularly in the event of mass trauma where service provision is limited. However, in the event that these individuals seek services, providers may use predictive factors to further foster mental health. For example, time may be spent in a therapeutic relationship exploring cognitive distortions about the experience (specifically reframing the thought of it as ruining a business to seeing it as a temporary setback and exploring what can be done to rebuild).

Consistent with previous findings (Frazier et al., 2004; Riolli et al., 2002), the second form of explored gains, perceived benefits, was predicted by high conscientiousness and also the seeking of social support. Surprisingly, actual receipt of support did not influence this perception, which appears to counter the work of Joseph et al. (1995), who suggested that the simple presence or absence of a support network predicted outcomes. The findings from this study indicate that it is not obtaining support but the seeking of support that appears to be of help. Perhaps in the previous report the survivors without an intact support network also failed to seek social support, thereby confounding the analyses. To resolve this question, one might examine whether those who seek social support and are also able to receive such support demonstrate the most gains as a result of an interactive relationship. Unfortunately, this could not be explored in this pilot study. The continuous nature of the variables and small sample size prohibit such exploration (Aguinis, 2004). However, the results of conducted analyses found that seeking social support accounted for significantly more variance in perception of benefits even when acquisition of support was already accounted for. This indicates that there is something unique in allowing oneself to disclose vulnerability and ask for help. This may mimic to some extent the experience of entering into a therapeutic relationship with a trained counselor and the ensuing sudden, early perception of gains in therapy (Ilardi \& Craighead, 1994, 1999).

The PBS is a relatively new measure and it is possible that the findings may have differed if another measure were used instead. However, the PBS has been found to be comparable psychometrically (supported, in part, by the high correlation between the measures). Furthermore, the PBS provides specific information not otherwise available from other common measures, capturing areas such as community closeness, family closeness, faith in people, and material gains. Finally, the PBS is advantageous for 
comparable measures in that it contains several filler items to decrease response bias.

Given the possibility that perception of benefits may simultaneously occur with mental distress (Borja et al., 2006), individuals who report benefits may still be in need of services and should not be excluded from screening or treatment efforts. Once in treatment, providers should consider overtly encouraging survivors of traumatic experiences to pursue other additional avenues of potential support. Current findings may also aid providers in conceptualizing why both positive and negative support may be associated with benefits in the aftermath of a traumatic experience (Borja et al., 2006). Based on our findings, it appears that seeking social support, regardless of whether it is obtained, is a key element in at least some aspects of mental health.

The sample employed in this study, although small, is significant for its diversity in age, income, and ethnic dispersion, and power analyses were excellent. Significant findings considering the small sample suggest that this may be an area for further investigation. However, some limitations are worth mentioning. The sample only included adults and it is possible that outcomes are quite different among children; future research examining this possibility is encouraged. Given that the sample was comprised of individuals who engaged in neighborhood cleanup efforts (a common sampling strategy; see Norris, 2007, for a discussion of disaster research methodology), participants may have been more likely to experience benefits from engaging in mutually supportive activities. Indeed, there was a higher mean score on the PBS; however, there was a large amount of variance representing various levels of perceived gains.

Furthermore, the length of time between exposure to the hurricane and participation in the study was relatively short (approximately 6 weeks), which may not have allowed for optimal attainment of gains among participants. It is notable that outcomes did not differ significantly as a function of property loss, in contrast to previous research (Briere \& Elliot, 2000; Norris et al., 1999). Finally, this study is the first to employ the NEO-FFI with a trauma population. In examining the literature, we found that the NEO-PI-R has previously been used with traumaexposed populations without such issues arising (Hyer et al., 1994; Talbert et al., 1993). However, we found no studies using the shorter NEO-FFI (derived from the NEO-PI-R). The two measures are thought to correlate very highly (Costa \& McCrae, 1992), but our findings suggest that this may not be true in a trauma population. We encourage further research into this matter, and the results of this study may offer an important point of comparison for such future studies.

\section{References}

American Psychological Association. (2002). Ethical principles of psychologists and code of conduct. Washington, DC: Author.

Aguinis, H. (2004). Moderated regression. New York: Guilford. Borja, S. E., Callahan, J. L., \& Long, P. J. (2006). Positive and negative adjustment and social support of sexual assault survivors. Journal of Traumatic Stress, 19, 905-914.

Bourque, L. B., Siegel, J. M., Kano, M., \& Wood, M. M. (2006). Weathering the storm: The impact of hurricanes on physical and mental health. Annals of the American Academy of Political and Social Science, 604, 129-150.

Brewin, C. R., Andrews, B., \& Valentine, J. D. (2000). Metaanalysis of risk factors for posttraumatic stress disorder in trauma-exposed adults. Journal of Counseling and Clinical Psychology, 68, 748-766.

Briere, J., \& Elliot, D. (2000). Prevalence, characteristics and long-term sequelae of natural disaster exposure in the general population. Journal of Traumatic Stress, 13, 661-679.

Cohen, S., Mermelstein, R., Kamarck, T., \& Hoberman, H. (1985). Measuring the functional components of social support. In I. G. Sarason \& B. R. Sarason (Eds.), Social support: Theory, research, and applications (pp. 73-94). Dordrecht, The Netherlands: Martinus Nijhoff.

Costa, P. T., Jr., \& McCrae, R. R. (1992). Revised NEO Personality Inventory (NEO-PI-R) and NEO Five-Factor Inventory (NEO-FFI). Odessa, FL: Psychological Assessment Resources.

Cryder, C. H., Kilmer, R. P., \& Tedeschi, R. G. (2006). An exploratory study of posttraumatic growth in children following a natural disaster. American Journal of Orthopsychiatry, 76, 65-69.

Dutton, M. A., Hohnecker, L. C., Halle, P. M., \& Burghardt, K. J. (1994). Traumatic responses among battered women who kill. Journal of Traumatic Stress, 7, 549-564.

Fauerbach, J. A., Lawrence, J. W., Schmidt, C. W., Munster, A. M., \& Costa, P. T. (2000). Personality predictors of injury-related posttraumatic stress disorder. Journal of Nervous and Mental Disease, 188, 510-517.

Frazier, P., Tashiero, T., Berman, M., Steger, M., \& Long, J. (2004). Correlates of levels and patterns of positive life changes following a sexual assault. Journal of Consulting and Clinical Psychology, 72, 19-30.

Funder, D. C. (2001). Personality. Annual Review of Psychology, 52, 197-221. 
Helgeson, V. S., Reynolds, K. A., \& Tomich, P. L. (2006). A meta-analytic review of benefit finding and growth. Journal of Consulting and Clinical Psychology, 74, 797-816.

Hyer, L., Braswell, L., Albrecht, B., Boyd, S., Boudewyns, P., \& Talbert, S. (1994). Relationship of NEO-PI to personality styles and severity of trauma in chronic PTSD victims. Journal of Clinical Psychology, 50, 669-707.

Ilardi, S. S., \& Craighead, W. E. (1994). The role of nonspecific factors in cognitive-behavior therapy for depression. Clinical Psychology: Science and Practice, 1, 138-156.

Ilardi, S. S., \& Craighead, W. E. (1999). Rapid early response, cognitive modification, and nonspecific factors in cognitive-behavior therapy for depression: A reply to Tang and Derubeis. Clinical Psychology: Science and Practice, 6, 295-299.

Joseph, S., Dalgleish, T., Thrasher, S., \& Yule, W. (1995). Crisis support and emotional reactions following trauma. Crisis Intervention, 1, 203-208.

Joseph, S., Linley, A. P., \& Harris, G. J. (2004). Understanding positive change following trauma and adversity: Structural clarification. Journal of Loss \& Trauma, 10, 83-96.

Keyes, C. L. M. (2002). The mental health continuum: From languishing to flourishing in life. Journal of Health and Social Behavior, 43, 207-222.

Keyes, C. L. M. (2005). Mental illness and/or mental health? Investigating axioms of the complete state model of health. Journal of Consulting and Clinical Psychology, 73, 539-548.

Linley, P. A., Joseph, S., Cooper, R., Harris, S., \& Meyer, C. (2003). Positive and negative changes following vicarious exposure to the September 11 terrorist attacks. Journal of Traumatic Stress, 16, 481-485.

McCubbin, H. I., Olson, D., \& Larsen, A. (1981). Family Crises Oriented Personal Evaluation Scale (F-COPES). In H. I. McCubbin, A. I. Thompson, \& M. A. McCubbin (Eds.), Family assessment: Resiliency, coping, and adaptation-Inventories for research and practice (pp. 455-508). Madison: University of Wisconsin Press.

McMillen, C. J., \& Cook, C. L. (2003). The positive by-products of spinal cord injury and their correlates. Rehabilitation Psychology, 48, 77-85.

McMillen, C. J., \& Fisher, R. H. (1998). The perceived benefit scales: Measuring perceived positive life changes after negative events. Social Work Research, 22, 173-186.

McMillen, C. J., Smith, E. M., \& Fisher, R. H. (1997). Perceived benefit and mental health after three types of disaster. Journal of Consulting and Clinical Psychology, 65, 733-739.

Miller, T. W., \& Kraus, R. F. (1994). Natural and environmental disasters: Psychological issues and clinical responses. Integrative Psychiatry, 10, 128-132.
Nightengale, J., \& Williams, R. M. (2000). Attitudes to emotional expression and personality in predicting posttraumatic stress disorder. British Journal of Clinical Psychology, 39, 243-254.

Norris, F. H. (2007). Disaster research methodology: Past progress and future directions. Retrieved May 28, 2007, from http:/www.redmh.org/research/general/methods.html.

Norris, F. H., Murphy, A. D., Baker, C. K., \& Perilla, J. L. (2004). Postdisaster PTSD over four waves of a panel study of Mexico's 1999 flood. Journal of Traumatic Stress, 17, 283-292.

Norris, F. H., Perilla, J. L., Riad, J.K., Kaniasty, K., \& Lavizzo, E. A. (1999). Stability and change in stress, resources, and psychological distress following natural disaster: Findings from Hurricane Andrew. Anxiety, Stress, E Coping: An International Journal, 12, 363-396.

O'Connor, B. P., \& Dyce, J. A. (2002). Tests of general and specific models of personality disorder configuration. In P. T. Costa Jr. \& T. A. Widiger (Eds.), Personality disorders and the five-factor model of personality (pp. 223-246). Washington, DC: American Psychological Association.

Ozer, E. J., Best, S. R., Lipsey, T. L., \& Weiss, D. S. (2003). Predictors of posttraumatic stress disorder and symptoms in adults: A meta analysis. Psychological Bulletin, 129, 52-73.

Riolli, L., Savick, V., \& Cepani, A. (2002). Resilience in the face of catastrophe: Optimism, personality, and coping in the Kosovo crisis. Journal of Applied Social Psychology, 32, 1604-1627.

SPSS. (2006). Statistical package for the social sciences, version 15.0 for Windows. Chicago: Author.

Talbert, F. S., Braswell, L. C., Albrecht, J. W., Hyer, L. A., \& Boudewyns, P. A. (1993). NEO-PI profiles in PTSD as a function of trauma level. Journal of Clinical Psychology, 49, 663-669.

Tedeschi, R. G., \& Calhoun, L. G. (1995). Trauma \& transformation: Growing in the aftermath of suffering. Thousand Oaks, CA: Sage.

TIME Poll Results: Hurricane Katrina. (2005, September 10). Time. Retrieved June 29, 2007, from http:/www.time.com/ time/press_releases/article/0,8599,1 103504,00.html.

Ullman, S. E. (1996). Social reactions, coping strategies, and self-blame attributions in adjustment to sexual assault. Psychology of Women Quarterly, 20, 505-526.

Vazquez, C., Cervellon, P., Perez-Sales, P., Vidales, D., \& Gaborit, M. (2001). Positive emotions in earthquake survivors in El Salvador. Journal of Anxiety Disorders, 19, 313-328.

Woodward, C., \& Joseph, S. (2003). Positive change processes and post-traumatic growth in people who have experienced childhood abuse: Understanding vehicles of change. Psychology and Psychotherapy: Theory, Research and Practice, 76, 267-283. 